\title{
Determination of the Viability of Chicken Feather as Oil Spill Clean-Up Sorbent for Crude Oil and its Lower Fractions
}

\author{
KELLE, HI; EBOATU, AN \\ Department of Pure and Applied Sciences, National Open University of Nigeria, Abuja, Nigeria. \\ Department of Pure and Industrial Chemistry, Nnamdi Azikiwe University, Awka, Anambra State, Nigeria. \\ Corresponding Author: henriettachima@yahoo.com
}

\begin{abstract}
In this study a comparative assessment was conducted between chicken feather and a conventional synthetic sorbent mat used in the oil industry to clean-up oil spill. The result of the study shows that chicken feather has higher oil sorption capacity and sorbed oil recoverability than the standard (synthetic sorbent mat), and competes well with the standard in terms of sorbed oil retainability. Chicken feather sorbed per unit mass $13.10 \pm 0.67 \mathrm{~g} / \mathrm{g}$ of crude oil, $11.15 \pm 0.84 \mathrm{~g} / \mathrm{g}$ of diesel and $9.70 \mathrm{~g} / \mathrm{g} \pm 0.91$ of kerosene while the standard sorbed per unit mass $11.50 \pm 0.54 \mathrm{~g} / \mathrm{g}$ of crude oil, $10.35 \pm 0.77 \mathrm{~g} / \mathrm{g}$ of diesel and $8.20 \pm 0.93 \mathrm{~g} / \mathrm{g}$ of kerosene. Sorbed oil recovered from a unit mass of chicken feather and standard are $12.25 \pm 0.38 \mathrm{~g} / \mathrm{g}$ of crude oil, $10.30 \pm 0.91 \mathrm{~g} / \mathrm{g}$ of diesel, $8.50 \pm 0.27 \mathrm{~g} / \mathrm{g}$ of kerosene and $9.67 \pm 0.36 \mathrm{~g} / \mathrm{g}$ of crude oil, $8.40 \pm 0.95 \mathrm{~g} / \mathrm{g}$ of diesel and $6.50 \pm 0.49 \mathrm{~g} / \mathrm{g}$ of kerosene respectively. Langmuir adsorption model and pseudo second order models fitted the process more precisely. Chicken feather competed favourably with the standard and both can be applied on land and aqueous environment in oil spill cleanup. It is an effective and viable sorbent for oil spill clean-up.
\end{abstract}

DOI: https://dx.doi.org/10.4314/jasem.v22i2.19

Copyright: Copyright (C) 2018 Egware et al. This is an open access article distributed under the Creative Commons Attribution License (CCL), which permits unrestricted use, distribution, and reproduction in any medium, provided the original work is properly cited

Dates: First received 01 December 2017; Received in revised form 07 January 2018; Accepted 07 February 2018

Keywords: Chicken feather, crude oil, diesel, adsorption kinetics, oil sorption capacity.

Spill of crude oil or its lower fractions; diesel or kerosene have detrimental effects on the environment. Consequently, serious efforts have been made to reduce the frequency and extent of oil spills near or on navigable waters (Gerard, 2016). Spilled oil requires clean-up using an efficient, cheaper and environment friendly material.

Chicken feathers are by-product waste of poultry processing plant and produced in large amount (Agrahari and Wadha, 2010). Worldwide 24 billion chickens are killed annually and around 8.5 billion tonnes of poultry feather are produced (Agrahari and Wadha, 2010; Prasanthi et al., 2016). According to some available figures of the USA Foreign Agricultural Service post reports, the total domestic per capita consumption of Chickens is $59 \mathrm{~kg}$ in the United States; $48 \mathrm{~kg}$ in the Saudi Arabia, $67 \mathrm{~kg}$ in Hong Kong, $69.7 \mathrm{~kg}$ in Israel, and $35.4 \mathrm{~kg}$ in Canada (USDA Foreign Agricultural Service, 2014). Nigeria consumes about 1.5 million tonnes of chicken annually out of which $30 \%$ (450,000 tonnes) are produced locally and efforts are been made to increase local production to meet demand (Thisday, 2017). The poultry feathers are dumped, used for land filling, incinerated or buried which involves problems in storage, handling, emissions control and ash disposal; burning poultry wastes may actually produce as much or more toxic air emissions than coal plants, for example, analysis conducted by the North Carolina Department of Environment and Natural Resources found that a $57 \mathrm{MW}$ poultry waste combustion plant emitted levels of carbon monoxide, particulate matter, nitrogen oxides, and carbon dioxide per unit of power generated that were higher than those for new coal plants ( Stingone and Wing, 2011). To determine the sorption capacity of a sorbent it needs to be compared (Volesky, 2004). This helps in efficient application of sorbents. Efficient application of sorbents requires knowledge of data on the sorbent sorption capacity and a good understanding on the basic mechanism behind the sorption capabilities (Singh et al., 2013). The aim of this study is to establish the viability and efficacy of chicken feather as an oil spill sorbent for crude and its lower fractions.

\section{MATERIALS AND METHODS}

Sample Collection and preparation: Chicken feathers were obtained from a chicken slaughter house located in Abraka market, Asaba, Delta state, Nigeria, where they were heaped as solid waste material. Crude oil was obtained from Shell Petroleum Development Company, Warri, Delta state, Nigeria, while diesel and kerosene were purchased from a filling station located in Asaba, Delta state Nigeria. Synthetic 
sorbent mat used as standard in the study was supplied by Department of Oil Spill Remediation, Shell Petroleum Development Company, Port Harcourt, Rivers State, Nigeria. The chicken feathers were washed, dried under the sun for three weeks and ground with a mechanical blender, not into particulate form but fluffy form.

Determination of Equilibrium Sorption Capacity of Crude Oil, Diesel and Kerosene onto Chicken Feather and Synthetic Sorbent Mat: One $\mathrm{dm}^{3}$ of crude oil, diesel and kerosene whose weight had been predetermined were each put in a pre-cleaned $2 \mathrm{dm}^{3}$ beaker. The weight of each sorbate was used as the initial concentration of each sorbate. Five (5) $\mathrm{g}$ of chicken feather/synthetic sorbent mat was weighed and added into the beaker and left for a required contact time at $28^{0} \mathrm{C}$. The contact times used in this study ranged from 10 to100 minutes, at 10 minutes interval. At the end of each contact time, the content in the beaker was passed through a sieve of $425 \mu \mathrm{m}$ into another pre-cleaned and pre-weighed 2 $\mathrm{dm}^{3}$ beaker and allowed to drain. The weight of the 2 $\mathrm{dm}^{3}$ beaker containing unsorbed sorbate was weighed and the weight of unsorbed sorbate obtained by weight difference. The weight of the unsorbed sorbate was used as final concentration of each sorbate.

For each contact time the amount of crude oil, diesel and kerosene sorbed onto a unit mass of chicken feather/synthetic sorbent mat was calculated from:

$\mathrm{q}=\frac{C_{i}-C_{f}}{M}$

Where $\mathrm{q}=$ the amount of oil sorbed onto a unit mass of chicken feather/synthetic sorbent mat, $C_{i}=$ initial concentration of oil in grams $(\mathrm{g}), C_{f}=$ final concentration of oil in grams $(\mathrm{g})$, From the plot of amount of oil sorbed onto a unit mass of chicken feather/synthetic sorbent mat against time, the amount of oil sorbed at equilibrium was obtained.

Determination of Equilibration time of Sorption of Crude Oil, Diesel and Kerosene onto Chicken feather and Synthetic Sorbent Mat: This was obtained from the plot of amount of oil sorbed onto a unit mass of chicken feather/synthetic sorbent mat against time, as the time corresponding with the amount of oil sorbed onto a unit mass of chicken feather/synthetic sorbent mat at equilibrium.

Determination of Recovery of Sorbed Crude Oil, Diesel and Kerosene from Chicken feather/Synthetic Sorbent Mat: The amount of sorbed crude oil, diesel and kerosene recovered from chicken feather/synthetic sorbent mat was determined by removing each sorbent from the sieve, weighing it and afterwards subjecting it to pressing using a carver hydraulic press, Model M, serial No. 12000 - 137, operated at a pressure of 25 tonnes, for five minutes, at $28{ }^{\circ} \mathrm{C}$. After pressing, the sorbent was re- weighed; the weight of sorbate recovered was determined by weight difference. The amount of sorbed crude oil, diesel and kerosene recovered per unit mass of chicken feather/synthetic sorbent mat was determined from the expression:

$\mathrm{q}=\frac{\text { Initial weight }- \text { Final weight }}{\text { Mass of sorbent }}$

The experiment was performed in triplicate, the average and standard deviation were calculated and used. The amount of sorbed oils retained per unit mass of chicken feather/synthetic sorbent mat was obtained from the expression: $\mathrm{q}=$ Quantity of oil sorbed per unit mass of chicken feather/synthetic sorbent mat- Quantity of sorbed oil recovered per unit mass of chicken feather/synthetic sorbent mat.

Determination of the sorption Process of Crude Oil, Diesel and Kerosene onto Chicken feather/Synthetic Sorbent Mat Using Adsorption Isotherm: To verify the sorption process of crude oil, diesel and kerosene onto chicken feather/synthetic sorbent mat, the linearized form of Langmuir, Freundlich, Elovich, Temkin and Dubinin-Radushkevich adsorption models were applied to the experimental data obtained. Usually to obtain experimental data to be fitted into an adsorption model, different initial concentrations of the sorbate and /or different mass of the sorbent is used during the experiment, so as to produce other values of equilibrium sorption capacity $\left(\mathrm{q}_{\mathrm{e}}\right)$ and equilibrium concentration $\left(\mathrm{C}_{\mathrm{e}}\right)$ at the end of the experiment. Five different initial concentrations of crude oil, diesel and kerosene were used to obtain different values of equilibrium sorption capacity $\left(\mathrm{q}_{\mathrm{e}}\right)$ and equilibrium concentration $\left(\mathrm{C}_{\mathrm{e}}\right)$. The experiment was conducted as mentioned above. The sorbate sorbent system was left to contact for one hour. The experiment was conducted in triplicate for each initial concentration and the average taken.

Kinetic Studies: In order to investigate the rate, mechanism of sorption and potentially controlling steps of the sorption such as mass transport, several kinetic models were tested including Lagergren pseudo-first-order, pseudo-second-order, intraparticle diffusion and liquid film diffusion models.

Determination of Sorption of Crude Oil, Diesel or Kerosene Displaced on Water, Onto Chicken feather 
and Synthetic Sorbent Mat: To ascertain the mopping behaviour of chicken feather and synthetic sorbent mat when crude oil, diesel and kerosene spill on water, that is, if chicken feather will sorb water while sorbing any of the oils, the experiment was repeated. 1 (one) $\mathrm{dm}^{3}$ of water was poured into a pre-weighed 2 $\mathrm{dm}^{3}$ beaker and weighed; the weight of water was obtained by difference in weight. $0.5 \mathrm{dm}^{3}$ of oil whose initial weight had been predetermined was added into the water in the beaker. Five grams of chicken feather/synthetic sorbent mat was weighed and added into the oil/water mixture and left for a contact time of 100 minutes.

\section{RESULTS AND DISCUSSION}

The equilibrium sorption capacity of the sorbates onto the sorbents, which is the oil sorption capacity of the sorbents, is presented in Fig.1. The amount of the oils sorbed at equilibrium onto a unit mass of chicken feather and the synthetic sorbent used as standard in the study is, chicken feather; $13.10 \mathrm{~g} / \mathrm{g}$ of crude oil at 60 minutes, $11.15 \mathrm{~g} / \mathrm{g}$ at 50 minutes and $9.70 \mathrm{~g} / \mathrm{g}$ at 60 minutes, while the standard is; $11.50 \mathrm{~g} / \mathrm{g}$ of crude oil at 40 minutes, $10.35 \mathrm{~g} / \mathrm{g}$ of diesel at 60 minutes and $8.20 \mathrm{~g} / \mathrm{g}$ of kerosene at 40 minutes. The result shows that chicken feather sorbed each of the sorbates more than the standard. This indicates that chicken feather has higher oil sorption capacity than the standard. The amount of material sorbed depends on a number of factors including the degree of attraction between sorbate and sorbent, the surface area exposed to mobile particles, the concentration of the contaminants, $\mathrm{pH}$ and temperature of the liquid phase (Livingston, 2005). Organic sorbates chemically bond to the sorbent, if the sorbate and sorbent have mutually reactive moieties (Brown, 1983). Variety of different types of attractive forces between the sorbate and sorbent results in sorption and the extent of these intermolecular attractions depends on molecular chain length and on surface area available for interaction (Weber et al, 1991). The larger the surface area and molecular chain length, the higher the sorption. Chicken feather and all feather are mainly composed of $91 \%$ protein (keratin), keratins are long chains of amino acids. Based on the side chain of an amino acid, it can be classified as hydrophobic, polar (hygroscopic) or charged (Thyagarajan et al, 2013). The side chains of the hydrophobic amino acids are nonpolar; mainly hydrocarbon. The polar amino acids side chains are hydrocarbons containing atom(s) that can form hydrogen bond. The side chain of the charged amino acids contains hydrocarbons carrying negative or positive charges. Chicken feather consist mainly of hydrocarbons $(60 \%)$, the oils studied are hydrocarbons, the hydrocarbon side chains accounts for the intermolecular bonds formed between chicken feather and the oils, leading to the sorption of the oils on chicken feather. FTIR spectrum of the standard reveals that it is a polyhydrocarbon (Kelle and Ogoko, 2017), the standard and the sorbates are composed mainly of hydrocarbons, hence will interact better leading to greater sorption of the oils than with chicken feather, however, the result shows that chicken feather has higher oil sorption capacity. This could be attributed to the morphological features, porosity and surface area of chicken feather. Morphological features of chicken feather shows that chicken feather is composed of three distinct units; the central shaft of the feather that runs the entire length of the feather and is attached to the calamus, the secondary structures, the barbs and the tertiary structures, the barbules (Tesfaye et al, 2017; Belarmino et al, 2012). Feather barbs show honeycomb hollow shaped hollow cells in the crosssection direction, the presence of a honeycomb structure will provide for the accumulations of liquids in its interior (Tesfaye et al, 2017; Belarmino et al, 2012). Therefore, the presence of voids; honeycombed shaped hollow cells aided chicken feather to sorb the oils by physical entanglement/occlusion within the void. It's possible that chicken feather has more voids than the standard, making it to sorb more of the oils. Chicken feather fractions are mesoporous and microporous (Tesfaye et al, 2017), while the standard is mesoporous (Kelle and Ogoko, 2017). Porous materials are classified into several kinds by their size; according to IUPAC notation, microporous materials have pore diameters less than $2 \mathrm{~nm}$ and macroporous materials have pore diameters of greater than $50 \mathrm{~nm}$, the mesoporous category lies in the middle. Thus, microporous materials have small pore volumes and diameters, hence, can sorb and store small molecules, limiting accessibility of large molecules, mesoporous material accommodates large molecules therefore accessibility of large molecules is easier (Lim et al, 2015; Somasundaran, 2006). The mesoporous characteristics of both sorbents would have aided the high sorption of the sorbates by the sorbents irrespective of the size of the molecules sorbed, however, chicken feather is able to sorb more of the sorbates because microporosity helps create larger surface; it leads to larger surface area, and larger surface area promotes interaction between sorbate and sorbent. The time at which the sorbents attained sorption equilibrium in each of the sorbates indicates that the standard (40 minutes) attained equilibrium at a lesser time compared with chicken feather (60 minutes). This is due to the mesoporous nature of the standard; the presence of the mesopores allows a fast sorption and in a very short time equilibrium is 
reached, meanwhile, small pore volume and diameter of micropoporous materials sorb and store small molecules, leading to gradual sorption (Lim et al, 2015). The combined sorption of the mesopores and micropores in chicken feather could have contributed to chicken feather competing well with the standard, but attaining equilibrium sorption at a longer time. Sorption is a function of concentration; sorption increases with increase in concentration (Johnson, 1990), here concentration of the sorbates is synonymous with the molecular chain length and viscousity of the sorbates. The sorption capacity of the sorbates onto the sorbents shows that it increases with chain length and viscousity of the sorbates. As chain length increases in a hydrocarbon, its surface area increases. This gives rise to increased intermolecular attraction. As intermolecular attraction increases, sorption increases.

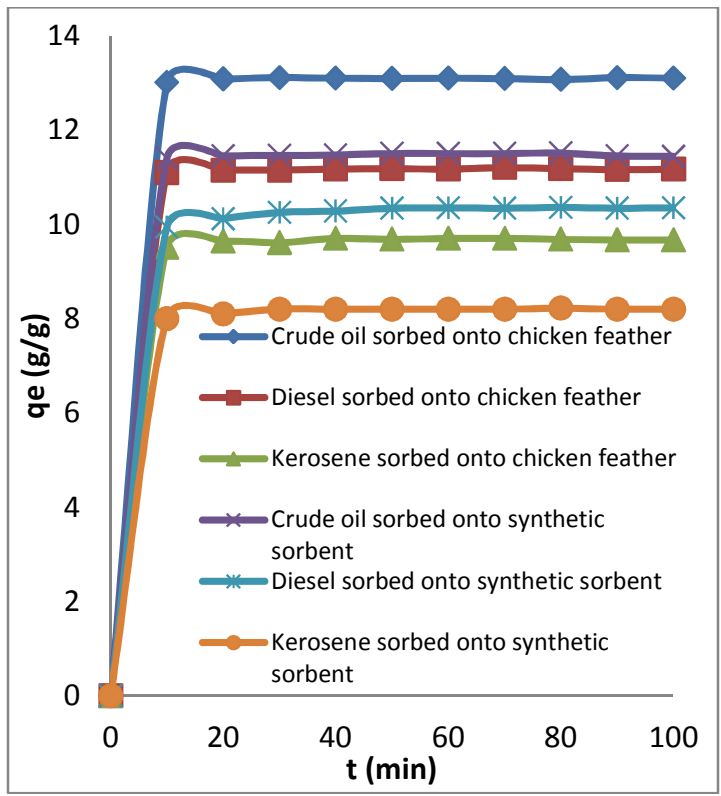

Fig 1: Amount of crude oil, diesel and kerosene sorbed onto a unit mass of chicken feather/ synthetic sorbent mat against time.

Among all the adsorption isotherms studied to investigate the sorption process of crude oil and its lower fractions onto chicken feather and the standard, the linearized form $C_{e} / q_{e}$ versus $C_{e}$ of the Langmuir adsorption isotherm produced the best fit isotherm with coefficient of correlation ranging from 0.9971 0.9983 . This shows that the sorption process follows the Langmuir isotherm, which implies that the interaction of both sorbents with the sorbates is monolayer adsorption, that is, one sorbate molecule is adsorbed on a layer of sorbent and there is no interaction between sorbed molecules. Sorbents can be compared by their respective maximum sorption capacity $q_{m}$ and b values obtained from the Langmuir equation (Volesky, 2004). The maximum sorption capacity $q_{m}$ is obtained from the isotherm model while $q_{e}$ is the equilibrium sorption capacity obtained from experiment (Jing et al, 2010). $q_{m}$ can be interpreted as the total number of binding sites that are available for sorption, and $q_{e}$ as the number of binding sites that are in fact occupied by the sorbate at the equilibrium concentration $C_{e}$ (Volesky, 2004). The constant $\mathrm{b}$ and $q_{m}$ are obtained from the slope and interception of the plot and are presented in Table 1 , the $b$ values obtained for each of the sorbent in each of the sorbate is the same. This implies that both sorbents have same affinity for the sorbates. Table 1 show that the calculated maximum sorption capacity value $\left(q_{m}\right)$ of chicken feather and the standard are slightly higher than their experimental equilibrium sorption capacity value. This further show that Langmuir isotherm provides better fit to the experimental values and can be used to verify the adsorption of crude oil, diesel and kerosene onto chicken feather and the standard. The higher $q_{m}$ values of chicken feather compared with those of the standard indicates that chicken feather has more total number of binding sites than the standard, which implies that, chicken feather has a larger surface area than the standard. This contributed to higher sorption capacity of chicken feather. The $q_{m}$ values for chicken feather and the standard show that chicken feather is a better sorbent than the standard. To further check the validity of the Langmuir model, the average percentage errors (APE) were calculated using the equilibrium concentration values $\mathrm{q}_{\mathrm{e}}$ and the Langmuir parameters $\mathrm{q}_{\mathrm{m}}$, according to the equation:

$$
\operatorname{APE}(\%)=\sum_{i=1}^{N} \frac{(q e), \exp -(q e), c a l / q e}{N} \quad X 100
$$

APE values obtained (Table 1) were low validating the Langmuir model. The favourable nature of sorption and affinity between the sorbate and sorbent can be expressed in terms of dimensionless separation factor equilibrium parameter of Hall et al, 1966 which is defined by the following relationship, $K_{R=1 / 1}+K_{a} C_{o}$, where $K_{R}$ is a dimensionless separation factor, $C_{o}$ is initial concentration $\left(\mathrm{mg} \mathrm{L}^{-1}\right)$ and $K_{a}$ is Langmuir constant $\left(\mathrm{L} \mathrm{mg}^{-1}\right)$. The values of $K_{R}$ indicates the type of isotherm to be irreversible $\left(K_{R}=0\right)$, favourable $\left(0<K_{R}<1\right)$, linear $\left(K_{R}=1\right)$ or unfavourable $\left(K_{R}>1\right)$. The dimensionless separation factors calculated for chicken feather and synthetic sorbent mat are presented in Table 1 . The $K_{R}$ values were less than 1 and greater than zero indicating favourable sorption: $12.25 \mathrm{~g} / \mathrm{g}$ crude oil $(93 \%$ of sorbed crude oil), $10.30 \mathrm{~g} / \mathrm{g}$ of diesel (92\% of sorbed diesel) and $8.50 \mathrm{~g} / \mathrm{g}$ of kerosene (87\% of sorbed 
kerosene) were recovered from a unit mass of chicken feather while $9.67 \mathrm{~g} / \mathrm{g}$ of crude oil (84\% of sorbed crude oil), $8.40 \mathrm{~g} / \mathrm{g}$ of diesel ( $81 \%$ of sorbed diesel) and $6.50 \mathrm{~g} / \mathrm{g}$ of kerosene (79 \% of sorbed kerosene) were recovered from a unit mass of synthetic sorbent mat.

Table 1: Parameters of Langmuir isotherm $\left(\mathrm{C}_{\mathrm{e}} / \mathrm{q}_{\mathrm{e}} \mathrm{vs} \mathrm{C}_{\mathrm{e}}\right)$ and equilibrium sorption capacity $\left(\mathrm{q}_{\mathrm{e}}\right)$ of crude oil, diesel and kerosene onto

\begin{tabular}{|c|c|c|c|c|c|c|}
\hline Sorption type & $b\left(\mathrm{~L} \mathrm{~g}^{-1}\right)$ & $\left.\begin{array}{l}q_{m} \\
1\end{array}\right)$ & $\mathbf{r}^{2}$ & $K_{R}$ & $q_{e}\left(\mathrm{~g} \mathrm{~g}^{-1}\right)$ & APE (\%) \\
\hline Sorption of crude onto chicken feather & 1.00 & 14.00 & 0.9983 & 0.0011 & $13.10 \pm 0.67$ & 0.046 \\
\hline Sorption of diesel onto chicken feather & 1.00 & 11.49 & 0.9982 & 0.0022 & $11.15 \pm 0.84$ & 0.024 \\
\hline Sorption of kerosene onto chicken feather & 1.00 & 10.00 & 0.997 & 0.0009 & $9.70 \pm 0.91$ & 0.0051 \\
\hline $\begin{array}{l}\text { Sorption of crude oil onto synthetic } \\
\text { sorbent }\end{array}$ & 1.00 & 11.62 & 0.9978 & 0.0011 & $11.50 \pm 0.54$ & 0.048 \\
\hline Sorption of diesel onto synthetic sorbent & 1.00 & 10.52 & 0.9979 & 0.0012 & $10.35 \pm 0.77$ & 0.005 \\
\hline $\begin{array}{l}\text { Sorption of kerosene onto synthetic } \\
\text { sorbent }\end{array}$ & 1.00 & 8.40 & 0.9971 & 0.0012 & $8.20 \pm 0.93$ & 0.0064 \\
\hline
\end{tabular}

Table 2: Pseudo - first order kinetic model (lagergren equation) for the sorption of crude oil, diesel and kerosene onto chicken feather and

\begin{tabular}{lllll}
\multicolumn{5}{c}{ standard. } \\
\hline Oil type & $\mathrm{q}_{\mathrm{e} e x p}(\mathrm{mg} / \mathrm{g})$ & $\mathrm{q}_{\mathrm{e}}$, Calc $(\mathrm{mg} / \mathrm{g})$ & $\mathrm{K}_{1}\left(\mathrm{~S}^{-1}\right)$ & $\mathrm{R}^{2}$ \\
\hline Crude oil (chicken feather) & 13100 & 244 & -0.0003 & 0.3101 \\
Diesel (chicken feather) & 11500 & 221.49 & -0.00045 & 0.4599 \\
kerosene (chicken feather) & 9700 & 544.57 & -0.0005 & 0.5946 \\
Crude oil (synthetic sorbent) & 11500 & 121.51 & -0.0066 & 0.013 \\
Diesel (synthetic sorbent) & 10350 & 735.09 & -0.0009 & 0.9811 \\
kerosene (synthetic sorbent) & 8200 & 365.03 & -0.001 & 1.00
\end{tabular}

Table 3: Pseudo - second order kinetic model (lagergren equation) for the sorption of crude oil, diesel and kerosene onto chicken feather

\begin{tabular}{llllll}
\hline \multicolumn{7}{c}{ and standard. } \\
\hline Oil type & $\mathrm{q}_{\mathrm{e} e x p}(\mathrm{mg} / \mathrm{g})$ & $\mathrm{q}_{\mathrm{e}}$, calc \\
Crude oil (chicken feather) & 13100 & 13200 & $\mathrm{~K}_{1}\left(\mathrm{~S}^{-1}\right)$ & $\mathrm{R}^{2}$ & $\mathrm{~h}$ \\
Diesel (chicken feather) & 11500 & 11640 & $8.6 \times 10^{-5}$ & 1 & 0.99 \\
Kerosene (chicken feather) & 9700 & 9900 & $1.0 \times 10^{-5}$ & 1 & 1 \\
Crude oil(synthetic sorbent) & 11500 & 12500 & $7.5 \times 10^{-8}$ & 1 & 1 \\
Diesel (synthetic sorbent) & 10340 & 10880 & $8.1 \times 10^{-8}$ & 1 & 0.99 \\
Kerosene (synthetic sorbent) & 8200 & 8333.33 & $1.4 \times 10^{-7}$ & 1 & 0.99 \\
\hline
\end{tabular}

Table 4: Intraparticle diffusion and liquid film diffusion for the sorption of crude oil, diesel and kerosene onto chicken feather and standard

\begin{tabular}{|c|c|c|c|}
\hline Oil type & Intraparticle diffusion $\mathrm{K}_{\mathrm{d}}\left(\mathrm{meq} \mathrm{g}^{-1} \mathrm{~S}^{1 / 2}\right)$ & $\begin{array}{l}\text { Intraparticle diffusion } \\
\mathrm{R}^{2}\end{array}$ & Liquid film diffusion $\mathrm{R}^{2}$ \\
\hline Crude oil (chicken feather) & 0.0077 & 0.3411 & 0.5634 \\
\hline Diesel (chicken feather) & 0.0016 & 0.5342 & 0.2174 \\
\hline Crude oil (synthetic sorbent) & 8.82 & 0.0236 & \#N/A \\
\hline Diesel (synthetic sorbent) & 9.06 & $0-4 \mathrm{E} 05$ & 0.8722 \\
\hline Kerosene (synthetic sorbent mat) & 9.85 & 0.6164 & 1.00 \\
\hline
\end{tabular}

More of the sorbed oils were recovered from chicken feather than the standard; this shows that chicken feather has higher sorbed oil recoverability than the standard. This may be attributed to the presence of honeycombed shaped hollow cells in addition to the mesoporous component of the structure of chicken feather, therefore more sorbates diffuse into the pores and effuse easily than in the sorbents. The amount of sorbed oils retained by a unit mass of chicken feather is about $0.80 \mathrm{~g} / \mathrm{g}$ of crude oil $(6.10 \%$ of sorbed crude oil), $0.80 \mathrm{~g} / \mathrm{g}$ of diesel $(7.17 \%$ of sorbed diesel), and $1.00 \mathrm{~g} / \mathrm{g}$ of kerosene $(10.30 \%$ of sorbed kerosene), while, $1.83 \mathrm{~g} / \mathrm{g}$ of crude oil ( $15 \%$ of sorbed crude oil), $1.94 \mathrm{~g} / \mathrm{g}$ of diesel (19\% of sorbed diesel) and $1.70 \mathrm{~g} / \mathrm{g}$ of kerosene ( $20 \%$ of sorbed kerosene) were retained by a unit mass of synthetic sorbent mat. This result shows that the standard retained more of the sorbed oils than chicken feather; however, chicken feather competes well with the standard in terms of sorbed oil retainability, suggesting the suitability of chicken feather as an oil spill clean-up sorbent.

Presented in Table $2-4$ is the result of kinetic studies of the rate and mechanism of sorption of crude oil, diesel and kerosene onto chicken feather and the standard. The pseudo first order kinetic model correlation coefficients $\left(\mathrm{R}^{2}\right)$ value (table 2 ) is low for chicken feather and the standard. This suggests that the sorption of crude oil, diesel and kerosene onto chicken feather and the standard is not a first order reaction. Moreover, the calculated equilibrium sorption capacities of both sorbents are lower than the experimental values (table 2) this validates that the sorption of crude oil, diesel and kerosene onto 
chicken feather and the synthetic sorbent mat is not a first order reaction.

Pseudo second order kinetic model correlation coefficient $\left(\mathrm{R}^{2}\right)$ and calculated equilibrium sorption capacities $\left(\mathrm{q}_{\mathrm{e}}\right.$ calc) values of the sorption of the oils onto chicken feather and the standard are presented in Table 3. The $\mathrm{R}^{2}$ values are 1.00 for each of the sorbents in sorption of each sorbate, this reveals that sorption of the oils onto the sorbents fits pseudosecond order kinetics. The calculated equilibrium sorption capacities $\left(\mathrm{q}_{\mathrm{e}}\right.$ calc $)$ of each oil onto the sorbents is higher than the experimental values (table 3 ), indicating the fit of pseudo- second order mechanism for the sorption of crude oil, diesel and kerosene onto chicken feather and the standard. This indicates that when the oils get to the surface of the sorbents due to the driving force obtained from the high concentration of the oils, it encounters fewer active sites or functional groups on the surface to be adsorbed. The high concentration of the oils on the surface then pushes the adsorbed oils from the surface through the pores (intraparticle diffusion) to the internal sites of the sorption.

Intraparticle diffusion is the rate-determining step when the plot is linear and passes through the origin (Dawodu and Akpomie, 2014). The plots did not pass through the origin and produced non-zero intercepts in both sorbents, suggesting that intraparticle diffusion is not the rate determining step. The deviation from the origin is due to the difference in mass transfer between the initial and final stages of the sorption process (Das and Mondal, 2011). The intraparticle diffusion model regression coefficient $\left(\mathrm{R}^{2}\right)$ obtained for the sorption of the sorbates onto chicken feather and the standard presented in tables 4 are moderate and low, this implies that intraparticle diffusion mechanism is not the rate determining step, but part of the rate determining step of the sorption process in both sorbents.

Plot of $\ln (1-F)$ as a function of $t$ with a zero intercept suggest that the kinetics of a sorption process are controlled by diffusion through the liquid film surface surrounding solid sorbent (Nwadiogbu et al, 2016). Non-zero intercepts were obtained for both chicken feather and the standard; this indicates that diffusion through the liquid film surface surrounding the sorbents is not the rate determining step. Liquid film regression coefficients $\left(\mathrm{R}^{2}\right)$ values of chicken feather and the standard are presented in table 4, these values are moderate for both chicken feather and the standard, indicating that surface sorption is not the rate determining step of the sorption process of crude oil, diesel and kerosene onto chicken feather and the standard, but was part of the rate determining step.

The amount of water sorbed together with each sorbate onto chicken feather and the standard in the experiment to determine suitable environment applicability of chicken feather and the standard are about the same; chicken feather sorbed $6.3 \mathrm{ml}(1.22 \mathrm{~g})$ of water while the standard sorbed $6 \mathrm{ml}(1.2 \mathrm{~g})$. These amounts are minimal for each of the sorbent, and it indicates that chicken feather competes well with the standard and could be employed to clean oil spill on water.

Conclusion: Chicken feather has higher oil sorption capacity and sorbed oil recoverability than the standard (synthetic sorbent mat). Chicken feather competes well with the standard in terms of sorbed oil retainability. The sorption of crude oil, diesel and kerosene onto chicken feather and the standard is by Langmuir adsorption model, and pseudo second order mechanism. Intraparticle diffusion model and liquid film diffusion model were parts of the rate determining steps of the sorption process of the oils onto chicken feather and the standard. Chicken feather and the standard can be applied on land and aqueous environment in oil spill clean-up. Chicken feather competed favourably with the standard; it is an effective and viable sorbent for oil spill clean-up.

\section{REFERENCES}

Agrahari, S; Wadhwa, N (2010). Degradation of Chicken Feather a Poultry Waste Product by Keratinolytic Bacteria Isolated from Dumping Site at Ghazipur Poultry Processing Plant. Int. J. of Poultry Sc, 9(1): 482-489.

Belarmino, DD; Ladchumananandasivam, R; Belarmino, LD; Pimentel, JRD, Da Rocha, BG; Galvao, AO; Andrade, SMB (2012). Physical and Morphological Structure of Chicken Feathers (Keratin Biofiber) in Natural, Chemically and Thermally Modified Forms. Mat. Sci. Appl. 3(2): $887-893$.

Brown, GI (1983). Introduction to Physical Chemistry. Longman, London.

Das, B; Mondal, NK (2011). Calcerous Soil as a New Adsorbent to Remove Lead from Aqueous Solution: Equilibrium, Kinetic and Thermodynamic Study. Unver J. Environ. Res. Technol. 1(4): 515-530.

Hall, KR; Eagleton, LC; Aerivos A; Vermeulen T (1966). Pore and Solid-Diffusion Kinetics in 
Fixed- Bed Adsorption under Constant-Pattern Conditions. Ind. Eng. Chem. Fund. 5:212-223.

Jing, H; Song, H; Liang, Z; Fuxing, G; Yuhshan, H (2010). Equilibrium and Thermodynamic Parameters of Adsorption of Methylene Blue Onto Rectorite. Fre. Environ. Bull.19 (11a):2651-2656.

Johnson, BB (1990). Effects of pH, Temperature, and Concentration on the adsorption of Cadmium on Goethite. Environ. Sci. Technol. 24(1): 112 -116.

Kelle, HI; Ogoko, EC (2017). Assessment of removal of crude oil and its lower fractions from land and aqueous medium using activated corncob carbon. FUW Trends Sci. Technol. J. 2(2): 937 -944.

Lim, Y; Chul cha, M; Chang, YJ (2015). Compressible and Monolithic Microporous Polymer Sponges Prepared Via One-Pot Synthesis. Sci. Rep. 5: 15957

Livingston, JV (2005). Trends in Water Pollution Research. Nova Science. New York.

Nwadiogbu, JO; Ajiwe, VIE; Okoye, PAC (2016). Removal of Crude Oil from Aqueous Medium by Sorption on Hydrophobic Corncobs: Equilibrium and Kinetic Studies. J. Taibah Uni. Sci. 10(1): 56-63.

Prasanthi, N.; Bhargavi, S; Machiraju PVS (2016). Chicken Feather Waste-A Threat to the Environment. Int. J. Innov. Res. Sci. Eng. Tech. 5(9): $1-9$.

Singh, V; Kendall, RJ; Hake, K; Ramkumar, S (2013). Crude Oil Sorption by Raw Cotton. Ind. Eng. Chem. Res. 52(18): 6277 - 6281.
Somasundaran, P (2006). Encyclopedia of Surface and Colloid Science. CRC Press. Florida.

Stingone, WA; Wing S (2011). Poultry Litter Incineration as a Source of Energy: Reviewing the Potential for Impacts on Environmental Health and Justice: A New Solution. J. Environ. Occupy. Health Policy. 21(1): 27 - 42.

Tesfaye, T; Sithole, B; Ramjugernath, D; Chunlall, V; (2017). Valorisation of Chicken Feathers: Characterisation of Physical Properties and Morphological Structure. J. Cleaner Prod. 149:349-365.

Thisday Newspaper, December 12, 2017.

Thyagarajan, D; Barathi, M; Sakthivadivu, R (2013). Scope of Poultry Waste Utilization. J. Agri. Vet. Sc. 6(5):29-35.

USDA Foreign Agricultural Service, 2014, in: Tesfaye, T; Sithole, B; Ramjugernath, D; Chunlall, V; (2017). Valorisation of Chicken Feathers: Characterisation of Physical Properties and Morphological Structure. J. Cleaner Prod. 149:349 - 365 .

Volesky, BV (2004). Sorption and Biosorption. BV Sorbex, Montreal.

Weber, WJ; McGinley, PM; Katz, LE (1991). Sorption Phenomena in Subsurface Systems: Concepts, Models and Effects on Contaminant Fate and Transport. Wat. Res. 25: 499-528. 